\title{
MECHANOCHEMICAL ACTIVATION OF PHARMACEUTICAL SUBSTANCES AS A FACTOR FOR MODIFICATION OF THEIR PHYSICAL, CHEMICAL AND BIOLOGICAL PROPERTIES
}

\author{
A. V. SYROESHKIN ${ }^{1}$, E. V. USPENSKAYA ${ }^{1}$, T. V. PLETENEVA ${ }^{1}$, M. A. MOROZOVA ${ }^{1}$, T. V. MAKSIMOVA ${ }^{1}$, A. M. \\ KOLDINA ${ }^{1}$, M. P. MAKAROVA ${ }^{1}$, O. V. LEVITSKAYA ${ }^{1}$, I. A. ZLATSKIY1, ${ }^{*}$
}

${ }^{1}$ Peoples Friendship University of Russia (RUDN University), 6 Miklukho-Maklaya St, Moscow, 117198, Russian Federation; ${ }^{2}$ State Institute of Genetic and Regenerative Medicine NAMS of Ukraine, 67 Vyshgorodska Str., Kyiv 04114, Ukraine

Email: zlatskiy@ukr.net

Received: 06 Feb 2019, Revised and Accepted: 18 Mar 2019

\section{ABSTRACT}

Objective: Study the influence of the mechanical preparation methods (grinding, fluidization) of solid pharmaceutical substances (PS) and herbal raw material on their physicochemical properties and biological activities.

Methods: Test substances and solvents-Lactose monohydrate (DFE Pharma, Germany). Sodium chloride, bendazol hydrochloride (all SigmaAldrich, USA) and herbal raw material (Callisia fragrans). The dispersity and native structure of pharmaceutical substances were analyzed by several methods: optical microscopy-Altami BIO 2 microscope (Russia); low angle laser light scattering (LALLS) method (Malvern Instruments, UK); Spirotox method-Quasichemical kinetic of cell transition of cellular biosensor Spirostomum ambiguum; Fourier-transform infrared spectroscopy-the analysis in the middle IR region was carried out using an IR Cary 630 Fourier spectrometer (Agilent Technologies, USA). The analysis of dried leaves of $C$. fragrans before and after mechanical activation was performed using Shimadzu EDX-7000 X-ray fluorescence spectrophotometer without mineralization (Shimadzu, Japan).

Results: It was established that the mechanical change, such as dispersion and drying, alters the biological activity of PS and herbal raw materials. The observed increase in the influence of the dispersed substance on the biosensor $S$. ambiguum is quantitatively estimated from the values of the activation energy (obsEa), which turns to be valued 1,5 $(\mathrm{P} \leq 0,05)$ times more than for the native form substance. In the study of the dependence of the availability of chemical elements $\mathrm{K}, \mathrm{Ca}, \mathrm{Zn}$ on the degree of dispersion of herbal raw materials was established a quantitative 4 -fold $(\mathrm{P} \leq 0,05)$ increase in the concentration of elements in mechano-activated raw materials.

Conclusion: By the example of the biological model of Spirotox (single-celled biosensor S. ambiguum) and herbal raw materials obtained from $C$. fragrans, the increase of biological activity of PS at the dispersion of initial preparations was proved.

Keywords: Pharmaceutical substances, Herbal raw material, Mechano-activation, Biological activities

(C) 2019 The Authors. Published by Innovare Academic Sciences Pvt Ltd. This is an open-access article under the CC BY license (http://creativecommons.org/licenses/by/4.0/) DOI: http://dx.doi.org/10.22159/ijap.2019v11i3.32413

\section{INTRODUCTION}

The relationship between the particle size and the reaction rate is manifested in the course of kinetic processes and at the ratecontrolling step of diffusion through the reaction product layer [1]. The influence of particle size on the physical and chemical properties of a substance can be explained by the presence of surface pressure acting on the substance [2]. This additional pressure leads to an increase in the Gibbs surface energy and, consequently, an increase in the pressure of saturated vapor over the solid-phase particles, an increase in the boiling point of the liquid phase and a decrease in the crystallization temperature of the solvent [3]. Other thermodynamic characteristics, i.e. the equilibrium constants of the solubility or redox processes and standard electrode potentials, also change $[4,5]$. The dispersion of substances also affects the bioavailability of active pharmaceutical ingredients (API) [6,7]. The degree of dispersion of PS determines the rate of dissolution, absorption into the bloodstream and the therapeutic effect of a therapeutic agent or raw material [810]. The effect of the mechanochemical activation of PS has not only theoretical but also important practical applications. This applies to quality control where the possible contribution of PS mechanochemical activation to its biological activity should be taken into account. The result of the possible change in mechanochemical activation of PS is manifested in the form of effect [10], which is characterized by a change in the rate of absorption, distribution, biotransformation, and excretion of the medicines. Development of methodological approaches to drugs quality control based on the possible change in mechanochemical activation of PS will improve pharmaceutical analysis and optimize their dosages, reducing the toxic load on the body.

In this paper, we are talking about a 2-component system "solventsolid substance" of varying degrees of dispersion. Our work was aimed to investigate the effects of sample preparation and mechanochemical activation of PS (lactose, sodium chloride, bendazol hydrochloride) on their biological activity using a singlecell biosensor (Spirotox model). The dependence of the availability of chemical elements $\mathrm{K}, \mathrm{Ca}$, $\mathrm{Zn}$ on the degree of dispersion of herbal raw materials $C$. fragrans was also studied.

Thus, the aim of the work was to study the influence of the mechanical preparation methods (grinding, fluidization) of solid pharmaceutical substances and herbal raw material on their physicochemical properties and biological activities.

\section{MATERIALS AND METHODS}

\section{Substances and solutions under research}

The PS was lactose monohydrate $\mathrm{C}_{12} \mathrm{H}_{22} \mathrm{O}_{11} \cdot \mathrm{H}_{2} \mathrm{O}$ (manufactured by DFE Pharma, Germany). Samples of lactose monohydrate SuperTab 30GR (DFE Pharma, Germany) were obtained by the technology of applying ultra-high aqueous-alcoholic dilutions of biologically active substances in the fluidized bed (made by Matera Medica Holding, Russia). The biological activity of seven samples of lactose monohydrate was investigated: 1-MM2571; 2-MM2571 samples saturated with intense release-active dilutions (RAD) of IFN- $\gamma$ Antibodies; 3-MM2571 sample saturated with RAD of the NO-synthase enzyme antibodies; 4-MM2571 sample saturated with phosphate buffered saline; 5-MM2571 sample, saturated with water; 6-MM2571 sample saturated with aqueousalcoholic solution; sample 7-MM25717-was not subjected to saturation. The concentration of the solutions under investigation was $7 \%$.

The PS of sodium chloride, $\mathrm{NaCl}$ (manufactured by Sigma-Aldritch, USA), solution concentration was $1 \%$.

The PS of bendazol hydrochloride (manufactured by Sigma-Aldritch, USA), solution concentration was $0.025 \%$. 
The solutions of the substances under the research were prepared by weighing on the analytical balance Acculab ATL-80d4 (Sartorius, Germany) and dissolving in water obtained at the Milli-Q System (Millipore; UK).

Herbal raw material: we used the leaves of $C$. fragrans (family Commelinaceae). The plants were cultivated in growth chambers (MIR-3, Russia) at a temperature of $20{ }^{\circ} \mathrm{C}$ and relative humidity of $60 \%$. The leaves of prepared dry raw materials were taken in the amount of $0.1576 \mathrm{~g}$ by weighing on the analytical balance Acculab ATL-80d4 (Sartorius, Germany).

\section{Optical microscopy}

The method of optical microscopy was used to determine the size and shape of the particles of the substances, which are individual characteristics of a substance. The studies were carried out using a microscope "Altami BIO 2, made in Russia" with 10x objective magnification. A sample of the substance was applied onto the slide and distributed over it so that the particles were in the same plane. The particles were observed in separate fields of view. For each series, there were examined 10 areas, each of them containing from 6 to 30 particles. Then, the microscope pictures were used to measure the length of the particles (the maximum particle size, oriented in parallel to the eyepiece scale from one end to the other) with the program "Altami Studio 3.3" and a USB camera (resolution 3 Mpix)-all made by Altami, Russia.

\section{Mechanochemical activation of PS}

\section{Dispersion of samples}

Microstructuring of the substances under the research was carried out by grinding the samples in a mechanical cutting mill in the sort of "free, direct impact" (according to Rumpf) [11] for $10 \mathrm{~min}$ in the isocratic mode.

\section{Drying of samples}

The samples were dried in Binder ED23 oven (Germany) according to the Pharmacopoeia technique [12]: for $2 \mathrm{~h}$ within the temperature range specified in the pharmacopoeial monograph for each of the substances. Then, the open weighing bottle together with the lid was placed in the desiccator for cooling for $50 \mathrm{~min}$, after which the weighing bottle was closed with the lid and weighed. Subsequent weighing was carried out after each hour of further drying until a constant mass was achieved.

The leaves of $C$. fragrans were dried under mild (natural) conditions at a temperature of $25^{\circ} \mathrm{C}$ for $5-7 \mathrm{~d}$ until the complete drying was achieved by weighing the sample once a day until a constant mass was reached. When completely dried, the leaves got easily ground into powder.

\section{Methods of leveling differences in sample preparation}

\section{Filtration}

The solutions were filtered through a submicron inert membrane filter (millex GV, pore size $0.22 \mu \mathrm{m}$, Merck Millipore, UK).

\section{Boiling}

Boiling of sodium chloride solutions was carried out over the flame of an alcohol burner for $0.5 \mathrm{~min}$.

\section{Laser diffraction method}

Particle size analysis (numerical and volume distribution of particle sizes/dimension spectra), dissolution kinetics of powders of different dispersity were recorded by the method of Low-angle laser light scattering (LALLS) on diffraction particle analyzers [13] using Master Sizer 2000 instrument, Zeta Sizer Nano ZS instrument (MALVERN Instruments, UK) and "Cluster-1"-IDL-1, laser meter of dispersion (manufactured by the Institute of Colloid Chemistry and Chemistry of Water, Ukraine; RUDN, Russia).

\section{Fourier-transform infrared spectroscopy}

The analysis in the mid-IR region was carried out using Cary 630 Fourier IR spectrometer (Agilent Technologies, USA) with an attenuated total reflection (ATR) attachment with a diamond crystal. The instrument control, measurement, and data processing were carried out using the Agilent MicroLab Expert software. The results in the field of terahertz spectrometry were obtained on Vertex 70 IR Fourier spectrometer (Bruker, Germany) equipped with a vacuum pump and a mercury lamp.

\section{X-ray fluorescence spectrophotometry}

The analysis of dried leaves of $C$. fragrans before and after mechanical activation was performed using Shimadzu EDX-7000 X-ray fluorescence spectrophotometer without mineralization (Shimadzu, Japan) based on a silicon drift detector with thermoelectric cooling with the PCEDX-Navi software (Japan). Specified conditions of measurement: current $100 \mu \mathrm{A}$, closed sample cell, collimator $10 \mathrm{~mm}$, air medium, Mylar and polypropylene films. The IAEA reference sample "NIST SRM 2976" was used to calibrate the results. The dried native sample was investigated for the trace element composition, then subjected to dispersion, and the same sample was investigated again. The studies were carried out on the quantitative change of the elements $\mathrm{K}, \mathrm{Ca}, \mathrm{Zn}$.

\section{The determination of the biological activity of PS using the $S$ ambiguum biosensor}

The model system of the $S$. ambiguum cell biosensor, strain by prof. N. B. Leonidov (Bioeffect State Research Institute), was used in the work. The test objects were cultivated in glass cylinders of $50 \mathrm{ml}$ with a concentration of $30-50$ cells $/ \mathrm{cm}^{3}$ at a temperature of $20-24$ ${ }^{\circ} \mathrm{C}$, feeding was carried out 2 times a week with 7-10 yeast granules. The strain was characterized by high mobility both in the horizontal and vertical directions. The installation for biotesting consisted of a 5 -well plate with a thermostatted membrane, Lauda Alpha A6 heating thermostat (Germany), and MBS-10 binocular (Russia). Lowpower daylight lamps $(\sim 10 \mathrm{~W})$ were used for lighting. In general, the experimental procedure was consistent with the generally accepted one [14] with some modifications [15].

All experiments were in accordance with ethical standards and principles adopted by EU Directives 2010/63/EU for animal testing.

\section{Statistics}

The findings were processed by the statistical methods using software packages of Origin Pro 9.1. Each value on the fig. represents «mean $\pm S D$ ».

\section{RESULTS AND DISCUSSION}

Previously, we published the results of the studies of the differences in laser light scattering by a certain method of laser diffraction and IR spectroscopy in samples of native and dispersed forms of lactose [16].

It was shown that intensive mechanical dispersion led to an increase in the dispersity of lactose monohydrate powders and to an increase in the specific surface area. It was found that the mechanochemical activation of the therapeutic substance powder had a pronounced effect on the structure and properties, which manifested as an increase in the dissolution rate [17]. This can help to improve the process characteristics of the substance powders and expand the range of their industrial use.

According to the results of IR spectroscopy, it was noted that the differences between lactose preparations identified in the far and middle IR ranges were due to differences in the organization of the supramolecular structures of lactose and water in the amorphous and quasicrystalline states [16].

Our further research was aimed at studying the biological activity of various PS during mechanochemical activation by dispersion.

Study of biological activity of native, dispersed and dried lactose monohydrate samples

The study of the biological activity of lactose monohydrate samples subjected to various sample preparation-drying and dispersion (fig. 1) showed that the greatest biological activity is characteristic of solutions of the dispersed and dried lactose monohydrate saturated with phosphate buffered saline (4). This may be due to the $\mathrm{pH}$ value of the media conducive to the vital activity of the protozoa. These lifetimes were the most consistent with the survival rate of the lactose 
monohydrate samples that did not undergo saturation $(1,7)$. The lowest survival rate of the biological object was observed in the solutions of lactose monohydrate samples saturated with a water-alcohol solution. This is due to the adverse effects of ethanol, which has a toxic effect on biological objects of different hierarchical levels [18]. The lifetime in solutions of native samples is higher in comparison with the corresponding solutions of dispersed and dried lactose monohydrate.
Accordingly, the biological activity of solutions of the dispersed lactose monohydrate samples exceeds that of the native samples, which may be associated with the mechanochemical activation [19]. The highest biological activity corresponds to the solutions of the dried lactose monohydrate samples. This effect of drying is explained by an increase in the mass of the corresponding weighted amounts for the preparation of the solutions, due to water loss.

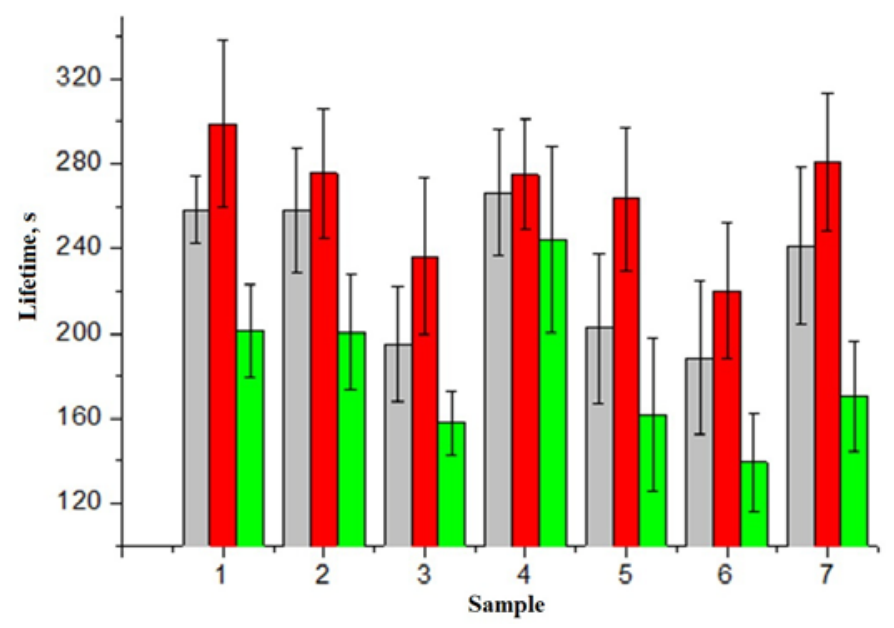

Fig. 1: Lifetime values of $S$. ambiguum in $7 \%$ aqueous solutions of the lactose monohydrate samples: 1, 7-different batches, not subjected to saturation; 2-saturated with release active dilution (RAD) of IFN- $\gamma$ antibodies; 3-saturated with RAD of NO-synthase enzyme antibodies; 4-saturated with phosphate buffered saline; 5-saturated with water; 6-saturated with water-alcohol solution. The native samples of lactose monohydrate are shown in red, dispersed samples-in gray, and dried samples-in green. $(\mathrm{mean} \pm \mathrm{SD}, \mathrm{n}=5, \mathrm{P}=\mathbf{0 . 9 5})$

It is found that the protozoa S. ambiguum react to the differences in PS sample preparation, in particular, lactose monohydrate. At the same time, the effect of such physical effects as dispersion and drying on the biological activity of PS solutions can be determined by the change in the survival rate of the biological objects.

Study of arrhenius kinetics of ligand-induced death of $S$. ambiguum in lactose monohydrate solutions

Earlier [16] we showed the temperature dependence of the process of ligand-induced cell death in $7 \%$ solutions of native and dispersed lactose monohydrate. The exponential dependence of the lifetime of the test object on the temperature was obtained, which made it possible to calculate the values of the apparent activation energy (Ea). Statistically significant differences (1.2 times) of values were obtained for the Ea of the solutions of native and dispersed samples of PS of lactose monohydrate.

In accordance with the laws of chemical kinetics, Ea represents the minimum energy exceeding the average energy required for the cell death process [20]. Consequently, lower values of the activation energy of the solution of the dispersed lactose monohydrate sample indicate its greater biological activity. The obtained results can be related to the processes occurring during the mechanochemical activation of the sample [21].

Thus, the influence of the mechanical grinding of a solid substance on the biological activity of its solutions was established. In order to level the differences in the history of sample preparation and to return to the concept of the true solution, the native and dispersed samples of lactose monohydrate were filtered through a submicron filter. The temperature dependence of the lifetime of the protozoa $S$. ambiguum in the temperature range $20 \div 32^{\circ} \mathrm{C}$ in increments of $2{ }^{\circ} \mathrm{C}$ in the solution of lactose monohydrate samples after the filtration has the form of an exponent (fig. 2). The linearization of the obtained exponentials in Arrhenius coordinates allowed determining the Ea values of the ligand-induced cell death process in the sample solutions after filtration according to the tangent of the inclination of the straight lines. The values are equal to $(67 \pm 1.0) \mathrm{kJ} / \mathrm{mol}$ for the native sample and $(66 \pm 1.5) \mathrm{kJ} / \mathrm{mol}$ for dispersed, i.e. almost the same. These values are statistically significantly different from the results obtained for the samples that were not subjected to filtration (table 1).
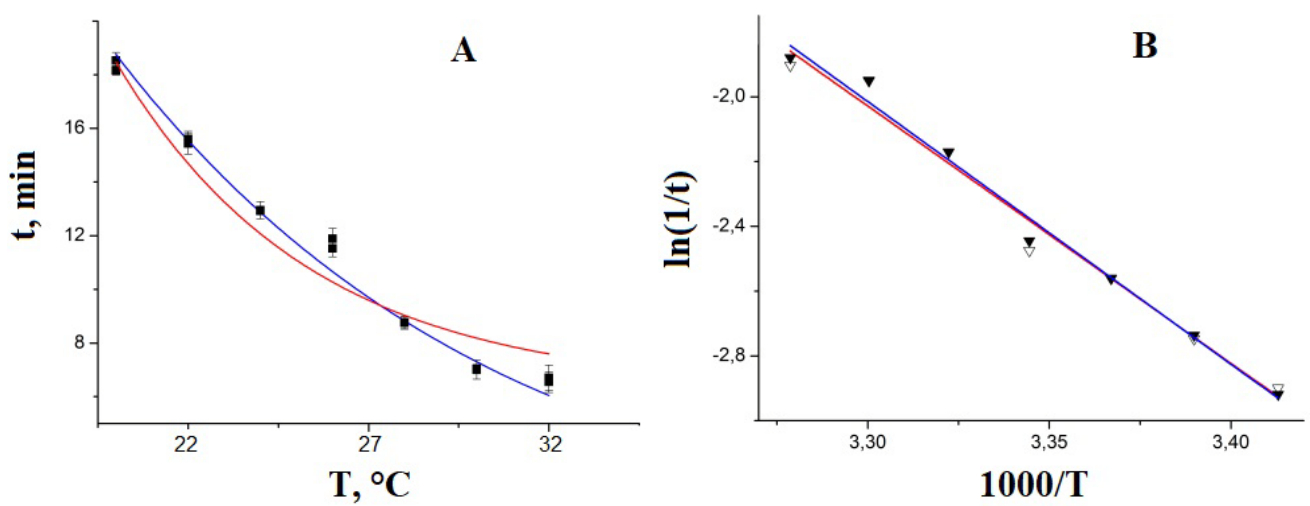

Fig. 2: The dependence of the time $(t)$ of the death of $S$. ambiguum on the temperature $(T)$ for the filtered 7\% aqueous solutions of lactose monohydrate in straight lines (A) and Arrhenius coordinates (B). Redline-dispersed sample, blue line-native sample. $($ mean $\pm S D, n=5, P=0.95)$ 
Table 1: Activation energies (Ea) of the death of $S$. ambiguum in the solutions subjected to different sample preparation (mean \pm SD)

\begin{tabular}{llll}
\hline Solutions & Ea, $\mathbf{k J} / \mathbf{m o l}$ & & \\
\cline { 2 - 3 } & $\begin{array}{l}\text { Native } \\
\text { sample }\end{array}$ & $\begin{array}{l}\text { Dispersed } \\
\text { sample }\end{array}$ & $\begin{array}{l}\text { Native filtered/Boiled } \\
\text { sample }\end{array}$ \\
\hline $\begin{array}{l}7 \% \text { aqueous solution of lactose monohydrate } \\
(\mathrm{n}=5, \mathrm{P}=0.95)\end{array}$ & $117 \pm 1.5$ & $101 \pm 1.5$ & $67 \pm 1.0$ \\
$\begin{array}{l}1 \% \text { aqueous solution of sodium chloride }(\mathrm{n}=5, \\
\mathrm{P}=0.95)\end{array}$ & $87 \pm 2.5$ & $68 \pm 1.0$ & $73 \pm 1.5$ \\
$\begin{array}{l}0.025 \% \text { aqueous solution of bendazol } \\
\text { hydrochloride }(\mathrm{n}=5, \mathrm{P}=0.90)\end{array}$ & $215 \pm 40$ & $94 \pm 18$ & - \\
\hline
\end{tabular}

Based on the results obtained, it can be concluded that, regardless of the initial state of the samples (unaffected and dispersed), the filtration leads to the equalization of the biological activity of the solutions. The obtained results can be related to the formation of water cluster structures differing in size and properties [22], which are destroyed during the filtration through a submicron filter with a certain fixed pore size $(0.22 \mu \mathrm{m})$.

The study of the influence of sample preparation on the biological activity of $\mathrm{NaCl}$ solutions

To confirm the established fact of the effect of dispersion on the biological activity of PS of organic nature-lactose monohydrate, there were conducted additional experiments with the pharmaceutical substance of inorganic nature-sodium chloride. The Spirotox method (the protozoa S. ambiguum) was used to analyze
$\mathrm{NaCl}$ solutions with $1 \%$ concentration of the native and dispersed natures. According to the results of the experiment [16], there was revealed a 1.4-fold decrease in the lifetime for the dispersed samples, which is similar to lactose monohydrate solutions. A statistically significant 1.3 -fold decrease in the Ea value of the solution of the dispersed PS sample of inorganic nature $(\mathrm{NaCl})$ in comparison with the native one was obtained. The achieved results can be explained by the mechanochemical activation, which contributes to a more complete dissolution, and, consequently, an increase in the absorption rate and bioavailability of the PS [22].

As in the experiments with lactose, an attempt was made to level the differences in the history of sample preparation for the native and dispersed sodium chloride samples by boiling their solutions. After cooling, the temperature dependence of the lifetime of the protozoa was obtained (fig. 3).
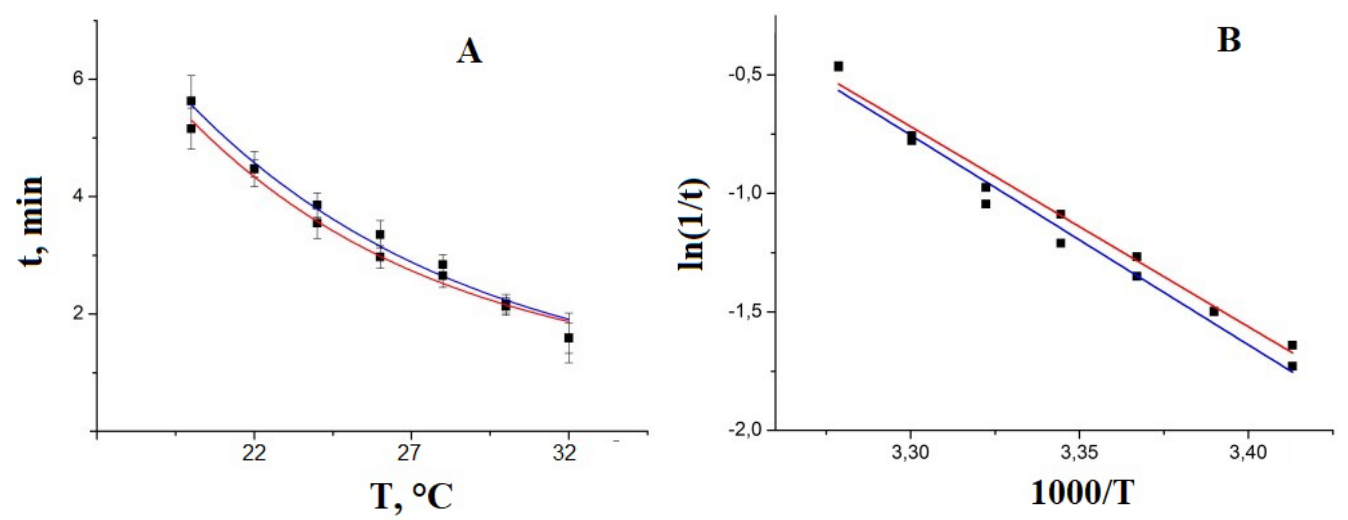

Fig. 3: The dependence of the time ( $\mathrm{t}$ ) of death of $S$. ambiguum on the temperature $(\mathrm{T})$ for the $1 \%$ aqueous solutions of boiled sodium chloride in straight lines (A) and Arrhenius coordinates $(B)$. Redline-dispersed sample, blue line-native sample. (mean $\pm S D, n=5, P=0.95)$

It follows from the obtained activation energy values that the sample preparation of $\mathrm{NaCl}$ solutions by boiling leads to leveling of the activation energy values, i.e. native and dispersed samples become indistinguishable (table 1). Thus, the leveling of the Ea values observed after the filtration of the lactose monohydrate solutions was also typical for the sodium chloride solutions subjected to boiling. It should be emphasized that both types of sample preparation of the solutions are accompanied by the destruction of giant heterogeneous water clusters, which is under isotope control [17].

The study of the influence of sample preparation on the biological activity of bendazol hydrochloride solutions

The study of the temperature dependence of the ligand-induced death of the test objects was continued in $0.025 \%$ aqueous solutions of bendazol hydrochloride in the temperature range $26 \div 32^{\circ} \mathrm{C}$ in increments of $2{ }^{\circ} \mathrm{C}$ (fig. 4). For this purpose, native samples of the substance and samples after dispersion were used.

Statistically significant differences in the Ea values (2.3-fold difference) of the ligand-induced death of test objects in the solutions of the pharmaceutical substance bendazol hydrochloride before and after the mechanochemical effect (table 1) were obtained. That is comparable with the data obtained on the biological activity of lactose and sodium chloride solutions.
Based on the laws of the Arrhenius kinetics, the effect of the activation on the biological activity of pharmaceutical substances and auxiliary substances of organic and inorganic nature is shown. The analysis of the obtained temperature dependences of the cell biosensor lifetime in the solutions of mechanically activated powder substances of API and excipients indicates the "structural" factor of the reduction of the ${ }^{\circ b 5} \mathrm{Ea}$ of the ligand-receptor interaction of $S$. ambiguum [23]. Grinding the powder of the substances in the sort of "free, direct impact" reduces the scale of heterogeneity, which determines the characteristic time of mass transfer of the reagents (ligands and cell receptor) to each other. This increases the reaction rate and reduces Ea [24]. After grinding, the free surface is not equilibrium and statically stable - processes of restructuring towards the equilibrium state begin in the near-surface layer. The ordering of the structure (transition "order-disorder-new order") significantly depends on the temperature of the system as a whole $[25,26]$.

The duration of the mechanochemical activation, as a result of heat exposure, is associated with the relaxation rate of residual stresses or elastic deformations, which lags behind the temperature change, thus showing the manifestation of slow relaxation phenomena discussed in detail in the literature [27, 28]. It is important to note that our results do not contradict the Debye-Hückel theory, who consider highly diluted solutions. In our studies, we deal with 
undiluted solutions, in which slow processes (reactions) take place. In this regard, the complete leveling of sample preparation
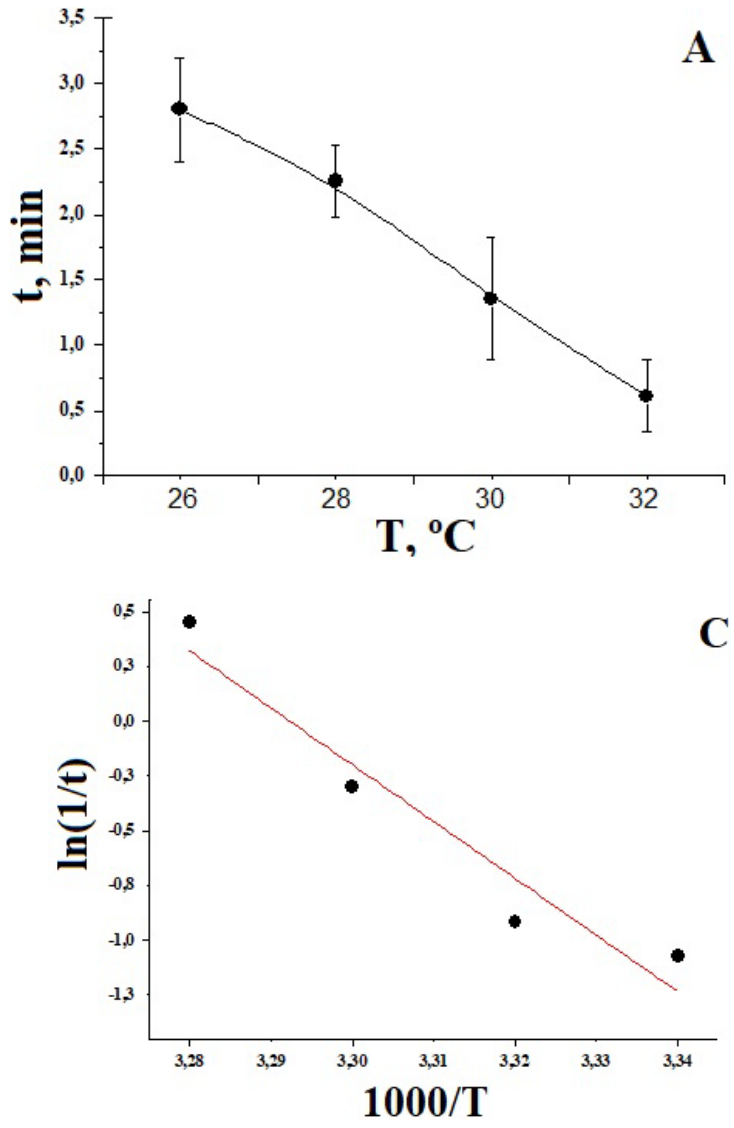

differences is achievable by mechanical filtration or boiling of the substance solution.
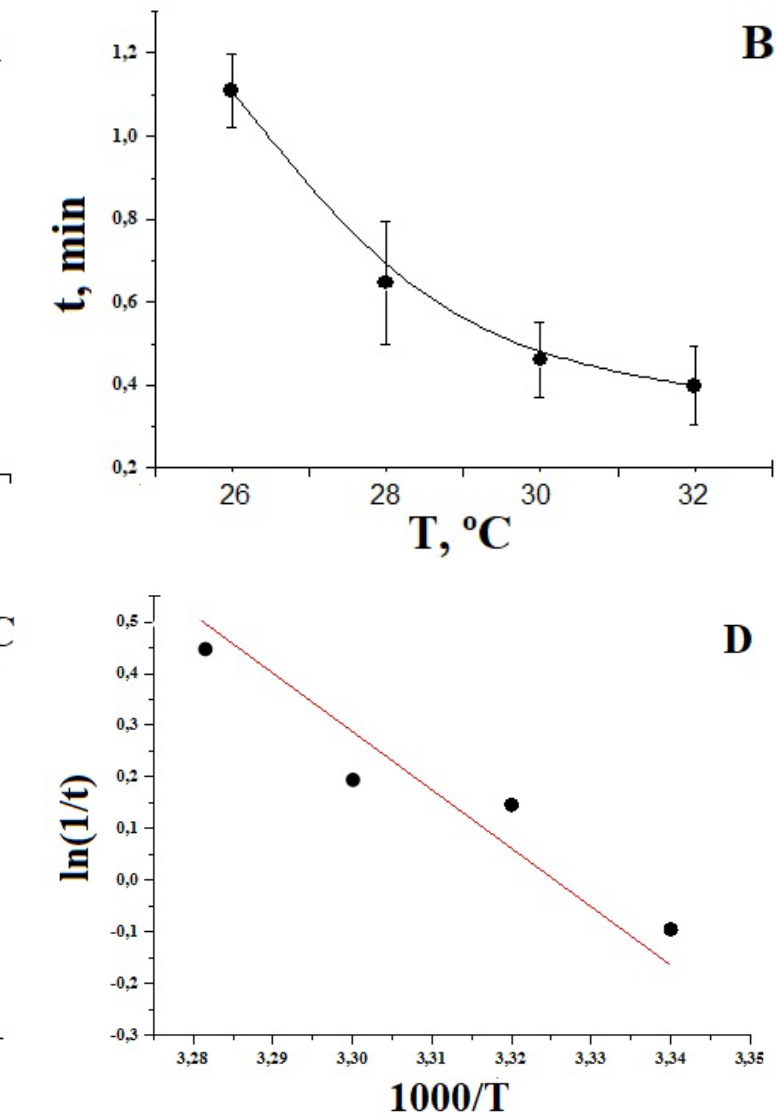

Fig. 4: Dependence of the time $(\mathrm{t})$ of death of $S$. ambiguum on the temperature $(\mathrm{T})$ in $0.025 \%$ aqueous bendazol hydrochloride solutions in the straight lines $(A, B)$ and in the Arrhenius $(C, D)$ coordinates before $(A, C)$ and after $(B, D)$ the mechanical activation $(\operatorname{mean} \pm S D, n=5, P=0.90)$

The dependence on the quantitative content of elements $\mathrm{K}, \mathrm{Ca}, \mathrm{Zn}$ on the degree of dispersion of herbal raw materials (C. fragrans)

The herbal raw materials based on leaves of $C$. fragrans have antioxidant and immunomodulatory effects [29] and can be used as a therapeutic substance. The results of studies of the herbal raw materials $C$. frangrans are presented in table 2, the concentrations of chemical elements $\mathrm{K}, \mathrm{Ca}, \mathrm{Zn}$ are given in mg calculated per kg of dry raw materials.

Table 2: Content of the elements $\mathrm{K}, \mathrm{Ca}, \mathrm{Zn}$ in dried leaves of $C$. fragrans before and after dispersion (mean $\pm \mathrm{SD}, \mathrm{n}=6, \mathrm{P}=0.95$ )

\begin{tabular}{lll}
\hline Element & Native sample & Dispersed sample \\
\hline $\mathrm{K}, \mathrm{mg} / \mathrm{kg}$ & $1989 \pm 13$ & $13656 \pm 130$ \\
$\mathrm{Ca}, \mathrm{mg} / \mathrm{kg}$ & $2873 \pm 26$ & $11268 \pm 260$ \\
$\mathrm{Zn}, \mathrm{mg} / \mathrm{kg}$ & $1.00 \pm 0.01$ & $4.91 \pm 0.35$ \\
\hline
\end{tabular}

It was found that the dispersed samples showed an increase of almost 4 or more times in the concentrations of all the studied elements. The explanation for this effect is that the chemical elements are not evenly distributed in plants: on the leaf surface and inside the cells [30]. The dispersion and homogenization of the sample allow increasing in the quantitative yield of the macro-and microelements under the research. This effect of the mechanoactivation of herbal raw materials can be used in pharmacy to increase the availability of the forms of administration of the elements.

\section{CONCLUSION}

As a result of the work, a statistically significant increase in the biological activity of solutions of PS of organic and inorganic nature due to the dispersion of solid samples was proved. Based on the physicochemical interpretation of the activation energy, it can be concluded that the smaller the obtained values of the apparent Ea cell death are, the easier it is to overcome the energy barrier of the ligand-receptor interaction process and the higher the biological activity of the corresponding substance is. The experiment proves that the dispersion of solids causes an increase in the biological activity of their solutions regardless of the nature of the PS. In the study of the dependence of the availability of chemical elements $\mathrm{K}$, $\mathrm{Ca}, \mathrm{Zn}$ on the degree of dispersion of herbal raw materials, there was found a 4 -fold $(\mathrm{P} \leq 0,05)$ quantitative increase in the concentration of elements in mechano-activated raw materials.

\section{ACKNOWLEDGMENT}

The publication has been prepared with the support of the «RUDN University Program 5-100».

\section{AUTHORS CONTRIBUTIONS}

All the author has contributed equally 


\section{CONFLICT OF INTERESTS}

Declared none

\section{REFERENCES}

1. Blaise C, Ferard JF. Small-scale freshwater toxicity investigations. Springer 2005;1:299-322.

2. Sonali Bharate S, Sandip Bharate B, Amrita Baja N. Interactions and incompatibilities of pharmaceutical excipients with active pharmaceutical ingredients: a comprehensive review. J Excipients Food Chem 2010;1:3-10.

3. Bazarov IP. Thermodynamics. Moscow: Vysshaya Shkola; 1991.

4. Sergeev GB. Nanochemistry. Amsterdam: Elsevier Science; 2006.

5. Cloves BJ, Divya B, Suman M, Venkataswamy K, Thyagaraju A. Study on phytochemicals, functional groups and mineral composition of Allium sativum (Garlic). Int J Cur Pharm Res 2017;9:42-5.

6. Zhu Y, Wang M, Zhang Y, Zeng J, Omari Siaw E, Yu J, et al. In vitro release and bioavailability of silybin from micelletemplated porous calcium phosphate microparticles. AAPS PharmSciTech 2016;17:1232-9.

7. Mulik A, Bhadekar R. Extracellular polymeric substance (EPS) from Kocuria sp. BRI 36.: a key component in heavy metal resistance. Int J Pharm Pharm Sci 2018;10:50-4.

8. Ivannikova EV, Zherdev VP, Boyko SS, Blynskaya EV, Turchinskaya KG, Alekseev KV. The study of pharmacokinetics and bioavailability in the creation of new original therapeutic agents with peptide structures and their optimal forms of administration. Pharmacokinet Pharmacodyn 2013;2:33.

9. Kripa KG, Sangeetha R, Chamundeeswari D. Pharmacognostical and physicochemical evaluation of the plant Leucas aspera. Asian J Pharm Clin Res 2016;9:263-8.

10. Fernandes BJD, Matthes ACS, Bighetti S, Fernandes JD, Lanchote VL, Pinto Lopes CR. Correlation between plasma tamoxifen concentration and tumor response in patients with breast cancer: at neoadjuvant treatment with tamoxifen. Int J Pharm Pharm Sci 2017;9:100-6.

11. Rumpf G. On the main physical issues in grinding. Frankfurt am Main: European meeting on grinding; 1962.

12. European Pharmacopoeia 8.0 V.1-2. Strasbourg: Council of Europe; 2014

13. Syroeshkin AV, Popov PI, Grebennikova TV. Laser diffraction for standardization of heterogeneous pharmaceutical preparations. J Pharm Biomed Anal 2005;37:927-30.

14. Nalecz Jawecki G, Sawicki J. Toxicity of inorganic compounds in the Spirotox test: a miniaturized version of the Spirostomum ambiguum test. Arch Environ Contam Toxicol 1998;34:1-5.

15. Goncharuk VV, Syroeshkin AV, Zlatskiy IA, Uspenskaya EV, Levitskaya OV, Dobrovolskiy VI, et al. Quasi-chemical description of the kinetics of cell death Spirostomum ambigua biosensor for biological activity of aqueous solutions. J Water Chem Technol 2017;39:97-102.
16. Syroeshkin AV, Uspenskaya EV, Pleteneva TV, Morozova MA, Zlatskiy IA, Koldina AM, et al. Mechanical transformation of compounds leading to physical, chemical and biological changes in pharmaceutical substances. Sci World J 2018. Doi:10.1155/2018/8905471

17. Uspenskaya EV, Anfimova EV, Syroeshkin AV, Pleteneva TV. Kinetics of pharmaceutical substance solubility in water with different hydrogen isotopes content. Indian J Pharm Sci 2018;80:318-24.

18. Sharma DK, Singh J, Raj P. Spectrophotometric determination of propranolol hydrochloride and metoprolol tartrate in pharmaceutical dosage forms, spiked water, and biological fluids. Int J Pharm Pharm Sci 2018;10:107-15.

19. Syroeshkin AV, Pleteneva TV, Uspenskaya EV, Levitskaya OV, Tribot-Laspiere MA, Zlatsky IA, et al. Polarimetric research of pharmaceutical substances in aqueous solutions with different water isotopologues ratio. Int J Appl Pharm 2018;10:243-8.

20. Bykanova SN, Suzdaleva OS, Seregina OB. The use of cellular biosensor Spirostomum ambigua to characterize the biological activity of the components of pharmaceuticals. Electronic J "Investigated In Russa" 2003;3:1114-29.

21. Shakhtshneider TP, Myz SA, Dyakonova MA, Boldyrev VV, Boldyreva EV, Nizovskii AI, et al. Mechanochemical preparation of organic-inorganic hybrid materials of drugs with inorganic oxides. Acta Phys Pol A 2011;119:272-8.

22. Meor Mmr, Tripathy M, Majeed A. The prospect, promises and hindrances of statin base molecules: look back to look forward. Int J Pharm Pharm Sci 2016;8:22-33.

23. Avakumov EG, Boldyrev VV, Boldyreva EV. Fundamentals of the mechanical activation, mechanosynthesis, and mechanochemical technologies. Novosibirsk: Publishing House of SB RAS; 2009.

24. Levitskaya OV, Syroeshkin AV, Pleteneva TV. Arrhenius kinetics as a bioactivity assessment criterion for drug substances and excipients. Pharm Chem J 2016;49:779-81.

25. Sali S, Gondkar S, Saudagar R. A review on: atrigel-the magical tool. Int J Curr Pharm Res 2018;10:38-42.

26. Goncharuk VV, Pleteneva TV, Grebennikova TV, Syroeshkin AV, Uspenskaya EV, Antipova NV, et al. Determination of biological activity of water having a different isotope ratio of protium and deuterium. J Water Chem Technol 2018;40:27-34.

27. Goncharuk VV, Pleteneva TV, Uspenskaya EV, Syroeshkin AV. Controlled chaos: heterogeneous catalysis. J Water Chem Technol 2017;39:325-30.

28. McCluney Kevin E, Sabo John L. Tracing water sources of terrestrial animal populations with stable isotopes: laboratory tests with crickets and spiders. PLoS One 2010;5:1-1.

29. Shantanova LN, Alekseeva EA, Khobrakova VB, Radnayeva DB. Stress-protective and immunomodulatory properties of Callisia fragans wood juice. Siberian Med J 2009;3:126-9.

30. Chuparina EV, Gunicheva TN. State and issues of X-ray fluorescence analysis of herbal raw materials. Anal Control 2004;8:211-26. 